$$
\text { By: }
$$

Dil Rowshan

B.Sc. (Hons), M. Sc. (Geography), Dhaka University, 1989

MURP, Bangladesh University of Engineering, 1994

\author{
A Major Research Paper \\ Presented to Ryerson University \\ In partial fulfillment for the degree of \\ Master of Planning \\ In \\ Urban Development
}

Toronto, Ontario, Canada, 2014

(C) Dil Rowshan, 2014 


\section{Author's Declaration}

I hereby declare that I am the sole author of this Major Research Paper. This is a true copy of the Major Research Paper, including any required final revisions, as accepted by my examiners.

I authorise Ryerson University to lend this paper to other institutions or individuals for the purpose of scholarly research.

I further authorise Ryerson University to reproduce this Major Research Paper by Photocopying or by other means, in total or in part, at the request of other institutions or individuals for the purpose of scholarly research.

I understand that my Major Research Paper may be made electronically available to the public. 


\title{
COMMUTING FOR WORK AND NEIGHBOURHOOD ENERGY CONSUMPTION
}

\author{
(C) Dil Rowshan, 2014 \\ Master of Planning in Urban Development \\ Ryerson University
}

\begin{abstract}
This study aimed to explore the impact of the Places to Grow Plan 2006 on travel behavior of the work commuters living in GTHA. A comparative analysis was done between the year 2001 and 2011 which represent the situations five year before and after the implementation of the Plan. Data were collected from Transportation Tomorrow Survey. The study revealed that in 2011, energy consumption by motorized vehicles increased in the Traffic Assessment Zones of GTHA around the Growth Centres designated by the Places to Grow Plan. Active transportation increased mainly in Toronto in 2011. It is apprehended that the intensification strategy of the Places to Grow Plan contributed in increasing the energy consumption of work commuters either by increasing the number of trips or length of trips made by motorized vehicles (including cars and different forms of transit) which also affect the Greenhouse Gas emissions in the atmosphere.
\end{abstract}

Key words: Motorized Vehicles, Active Transportation Mode, and Energy Consumption. 


\section{Acknowledgements}

I would like to extend my deep gratitude to Dr. Raktim Mitra for his valuable advice, support and constant encouragement. The scholarly comments and suggestions of Dr. Mitra have increased the depth of this study.

I would also like to thank Dr. Pamela Robinson, MCIP, RPP, Graduate Program Director, Department of Urban and Regional Planning, for her comments and support.

I would like to express my appreciation for Mr. Noel Damba, Data and GIS Technician, Ryerson Library for his technical assistance during the preparation of the Maps.

I want to thank my friend Dr. Lubna Daraz for her kind assistance during editing. Finally I want to thank my husband and daughters for their constant encouragement and support. 


\section{TABLE OF CONTENTS}

\section{Chapter One: Introduction}

1.1 Background

1.2 Objectives of the Study

1.3 Expected Contribution to Knowledge

1

4

4

6

Chapter Two: Literature Review

2.1 Introduction

6

2.2 Growth Planning and Travelling in GTHA

2.3 The Big Move: Transforming Transportation in the Greater Toronto and Hamilton Area

2.4 Land-use Planning, Active Transportation and Transit Use

2.5 Energy Consumption by Transportation Modes

Chapter Three: Methodology

3.1 Justification of Research Topic

3.2 Data

3.3 Data Analysis and Presentation

3.4 Limitations

\section{Chapter Four: Findings}

4.1 Energy Consumption in GTHA

4.2 Mode Share

4.3 Vehicle Ownership in GTHA

4.4 Vehicle Kilometer Travelled by Various Travel Modes 23

4.4.1 Commuting by Personal Automobiles 23

4.4.2 Commuting by GO Rail only 24

4.4.3 Commuting by Transit Excluding GO 25

4.5 Commuting by Waking and Cycling 27

4.6 Average Energy Use by Motorized Vehicles (in BTU and Kilocalories) 28

4.7 Energy Consumption by Active Transportation Modes 33

4.8 Growth Plan for GTHA and Average Energy Consumption 36

Chapter Five: Summary and Conclusion 38

$\begin{array}{ll}\text { Bibliography } & 41\end{array}$ 
Table 4.1 Growth of VKT of Auto Drivers 23

Table 4.2 Growth Trend of VKT by GO Rail only 25

Table 4.3 Growth Trend of VKT by Transit Excluding GO 26

Table 4.4 Growth Trend of Active Transportation 27 
Figure 1.1 Places to Grow Plan Area 2

Figure 1.2 Urban Growth Centres 2

Figure 1.3 Canadian GHG Emissions Breakdown 3

Figure 1.4 Canadian GHG Emissions by Transportation Sector 3

Figure 2.1 Conceptual Transport Energy Model 11

$\begin{array}{ll}\text { Figure 4.1 Mode Share in GTHA } & 21\end{array}$

Figure 4.2 Vehicle Ownership Trend 22

Figure 4.3 Changes in VKT of Auto Drivers 24

Figure 4.4 VKT Change for GO Rail only 25

Figure 4.5 VKT Change for Transit Excluding GO 26

Figure 4.6 Increase of Active Transportation (KM Travelled) 28

Figure 4.7 Energy Burned by Motorized Vehicles in $2001 \quad 30$

Figure 4.8 Energy Burned by Motorized Vehicles in 2011

Figure 4.9 Growth Centres and Energy Burned by Motorized Vehicles in 2011

Figure 4.10. Energy Burned by Active Transportation in 2001

Figure 4.11 Energy Burned by Active Transportation in 2011 


\section{Chapter One: Introduction}

\subsection{Background}

Movement in the urban areas originate for various purposes. People commute for work, education, leisure and many other reasons. Commuting involves different transportation modes and leads to emission of Green House Gases (GHG). Work commute is important because for obvious reasons, the frequency of occurrence and geographic area covered by such trips are extensive. According to National Household Survey 2011, about 15. 4 million Canadians commute to work and about 74.4 percent of commuters used private vehicles. Public transit users constituted only 12 percent of the commuters in 2011.According to the same survey only 5.7 percent commuters walked to work in 2011 and 1.3 percent cycled (Statistics Canada, 2012). Modal choices for commuting are related with population and concentration of employment opportunities in urban areas and bear an important influence on air quality. The Greater Toronto and Hamilton (GTHA) area having a population of six million, is a fast growing area which include two single-tier municipalities (Toronto and Hamilton) and four regional municipalities (Durham, Halton, Peel and York). Another 24 lower-tier municipalities are also tied to planning decisions taken for GTHA (Metrolinx, 2008). Plans and Policies are therefore directed towards sustainable development of areas falling under GTHA. The Places to Grow: Growth Plan for the Golden Horseshoe 2006 was prepared under the Places to Grow Act 2005, to accrue the positive impacts of growth which will naturally emerge and manage the negative aspects linked with growth such as traffic congestion, deterioration of air and water quality, and disappearance of agricultural lands and resources (Ontario Ministry of Infrastructure. 2013). The plan identifies selected urban areas as future Urban Growth centres which will experience greater population and economic growth (Figure 1.1 and 1.2). 


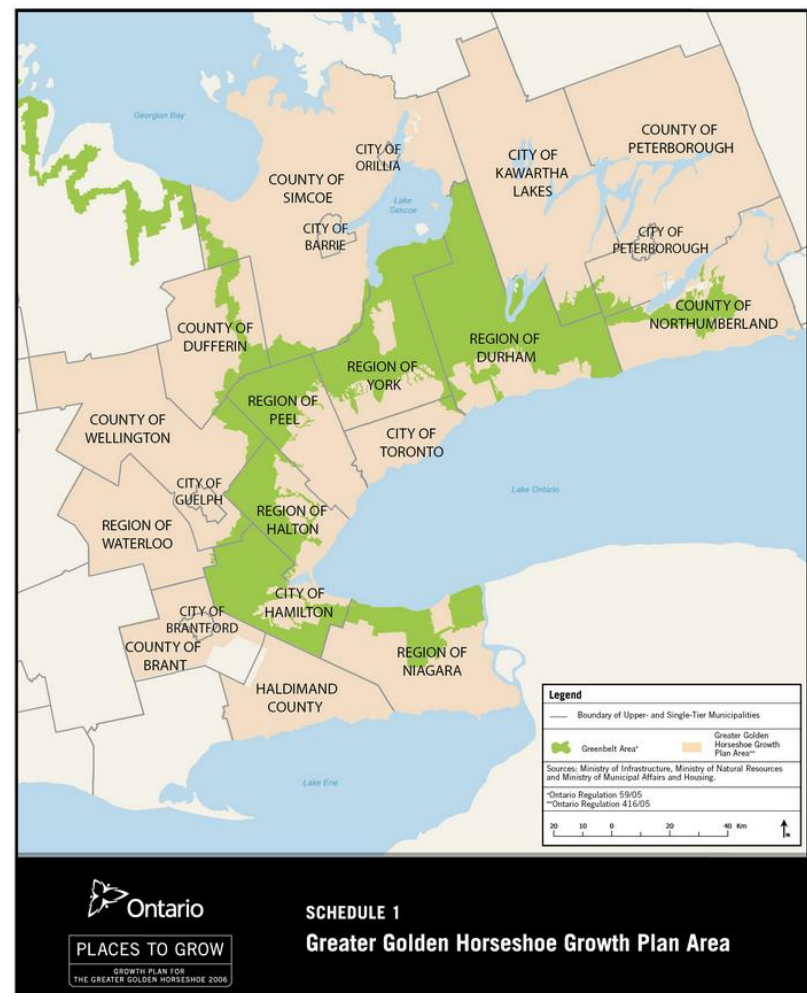

Figure 1.1 Places to Grow Plan Area

Source: Ontario Ministry of Infrastructure, (2013).

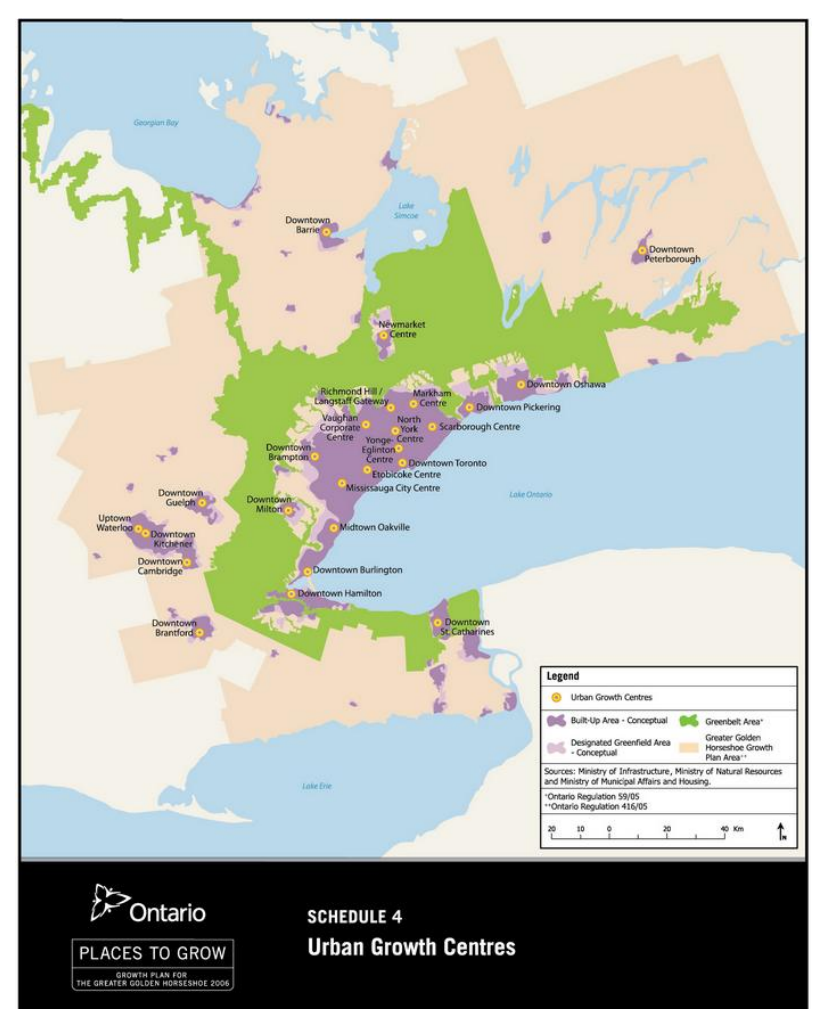

Figure 1.2 Urban Growth Centres

Source: Ontario Ministry of Infrastructure, (2013).

The Places to Grow Plan envisioned that the Growth Centres will attract population and employment opportunities as an outcome of the intensification strategy (Ontario Ministry of Infrastructure, 2013). One of the expected outcomes of this plan was that people would travel less or use alternative transportations mode, potentially leading to an overall reduction in the transportation related environmental pollution. Transportation is the second most dominant sector emitting GHG in the atmosphere (Environment Canada, 2014) (Figure 1.3) and among 
various transportation modes, road transportation is the prime emitter of $\mathrm{CO}_{2}$ (Environment Canada, 2014) (Figure 1.4).
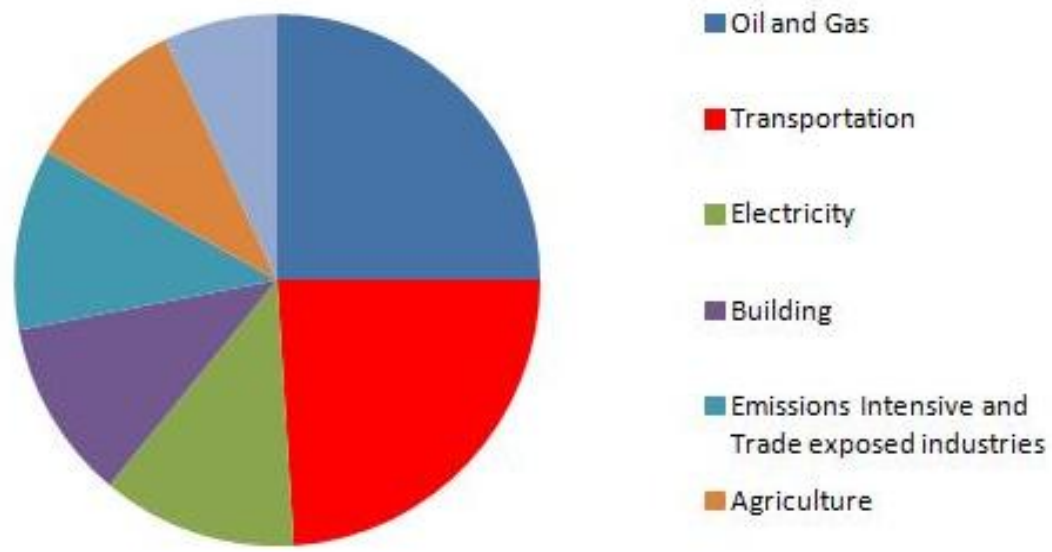

Figure 1.3. Canadian GHG Emissions Breakdown

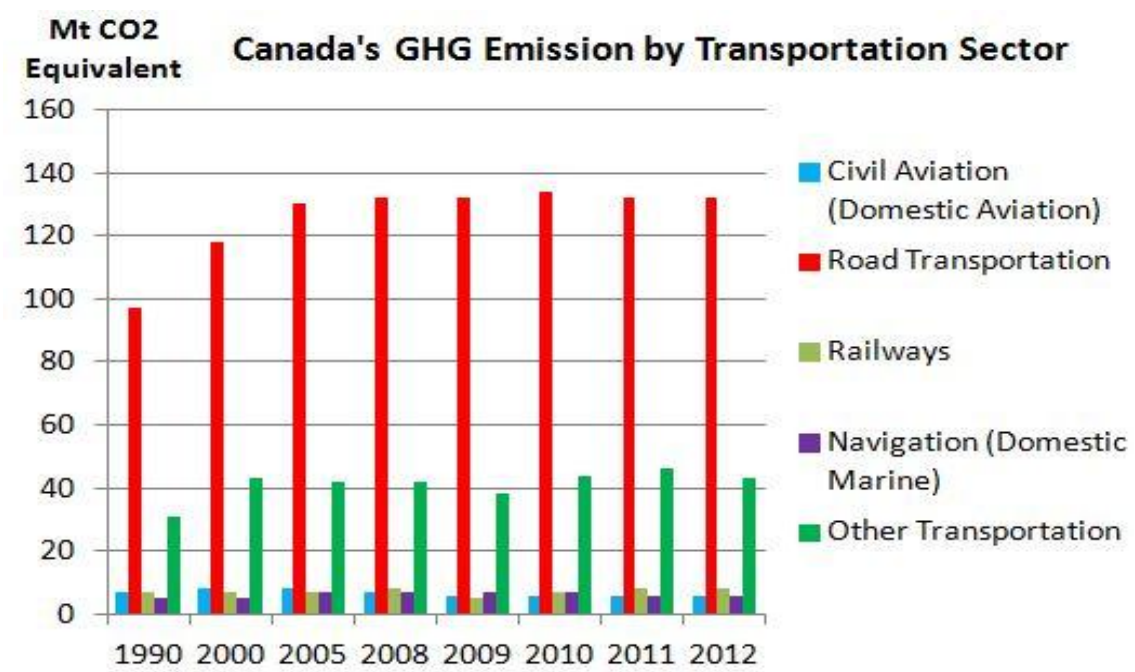

Figure 1.4. Canada`s GHG Emission by Transportation Sector

With the growing trend of population and required facilities to support these population, need for transportation to commute for work is emerging as a planning issue (Ontario Ministry of Infrastructure, 2013.; Metrolinx, 2012). The present study intends to focus on the travel 
behaviour related with work commute occurring in the GTHA. The results will indicate the modal choice and explore the amount of energy used through fossil fuel burning by motorized vehicle users and carbohydrate burning by active transportation users in the study area.

\subsection{Objectives of the Study}

The objectives of this proposed study are:

(i) To explore the short term impact of intensification strategy of "Places to Grow: The Growth Plan for the Greater Golden Horseshoe, 2006" on the travel behaviour of work commuters living in GTHA. The impact will be identified in terms of modal choice and Vehicle Kilometer Travelled by the commuters. A comparative analysis will be done on situations 5 year before and after the implementation of the plan.

(ii) To estimate energy consumption that can be attributed to commuting to work, and explore spatial patterns of this commute related emissions. The scale of analysis will be the Traffic Assessment Zones (TAZs).

\subsection{Expected Contribution to Knowledge}

Energy used by motorized transportation and active transportation bear two different types of implications. Energy used for active mode of transportation (i.e., carbohydrate) has important health benefits (Toronto Public Health, 2012B). It also contributes in sustaining the air quality by not adding more GHG gases to the atmosphere while the motorized transportation generated harmful GHG gases and contributes to climate change (Frank, et.al, 2010). The present study will explore average energy consumption by motorized vehicles and active transportation in the 
TAZs in GTHA. The final results will graphically show the pattern of energy consumption across the GTHA as well as the change in travel behavior of people living in GTHA between 2001 and 2011. The findings from this study will enable policy makers to explore the sustainability of transportation practice and intensification strategy of Places to Grow Plan. 


\section{Chapter Two: Literature Review}

\subsection{Introduction}

In recent years movement of pedestrians and the walking environment is getting attention of many researchers. Vehicular movement account for a very significant part of GHG emission (Environment Canada, 2014). Researchers are now turning to active transportation which includes any form of human-powered transportation - walking, cycling, using a wheelchair, skating or skateboarding as a means to offset carbon foot print at the neighbourhood level. Active transportation has multi-dimensional community benefits (Ontario Professional Planners Institute, 2011). It is an option for physical activity which can influence the traveller's health and wellbeing. Active transportation is a sustainable transportation mode which can help reduce GHG emissions by reducing dependency on motorized vehicles. It has been found that each Canadian makes an average of 2,000 trips of less than $3 \mathrm{~km}$ each year.(Ontario Professional Planners Institute, 2011). A modal shift towards active transportation, coupled with public transit and the use of transportation demand management programs (e.g. carpooling) may increase the capacity and efficiency of transportation system in terms of financial and environmental benefits (Ontario Professional Planners Institute, 2011).

\subsection{Growth Planning and Travelling in GTHA:}

"Places to Grow: The Growth Plan for the Greater Golden Horseshoe, 2006" offers the guiding principles of regional development in the GTHA. The Growth Centres that are proposed in the plan, are made a part of Official Plans of concerned Municipalities of GTHA and are the focal areas of investment in region-wide public services as well as commercial, recreational, cultural and entertainment uses so that they can accommodate and support major transit infrastructure 
(Ontario Ministry of Infrastructure, 2013). They are also expected to serve as high density major employment centres that will attract provincially, nationally or internationally significant employment uses. It is expected that by 2031, these Growth Centres will attain a growth density of 400 residents and jobs combined per hectare for each of the Growth Centres in the City of Toronto and 200 residents and jobs combined per hectare for the Growth Centres located in the Downtowns of Brampton, Burlington, Hamilton, Milton, Oshawa, Pickering, Richmond Hill/Langstaff Gateway, Kitchener, Markham Centre, Mississauga City Centre, Newmarket Centre, Midtown Oakville, , Vaughan Corporate Centre, and Uptown Waterloo.

The plan also raises a concern about the growing number of automobiles and longer commutes. This plan supports transit-supportive densities and a healthy mix of residential and employment land uses. It suggests a transportation network that would link urban growth centres through an extensive multi-modal system anchored by efficient public transit, together with highway systems for moving people and goods. In this plan walking and cycling is considered as a practical element of urban transportation system. With revitalization of growth centres, intensification of existing built up areas, intensification corridors, major transit station areas, Brownfield and grey-fields sites, urban areas are expected to become more accommodating for mixed-use and transit supportive development. The term "Transit Supportive" is used to refer to compact, mixed use development that has a high level of employment and residential densities to support frequent transit service. From urban design perspective it refers to design principles that make urban development more accessible to transit users, such as roads laid out in a grid network rather than a discontinuous network; pedestrian-friendly built environment along roads to encourage walking to transit; reduced setbacks and placing parking at the sides/rear of 
buildings; and improved access between arterial roads and interior blocks in residential areas (Ontario Ministry of Infrastructure, 2013).The Plan envisioned that with proposed minimum gross density targets of residents and jobs in the in the growth centres, more people will be walking, cycling and using transit for day to day transportation. The plan supports multi modal use if and where possible. In order to reduce trip distance and time, and increase the modal share of alternatives to the automobile, municipalities are encouraged to incorporate transportation demand management policies (Ontario Ministry of Infrastructure, 2013).

\subsection{The Big Move: Transforming Transportation in the Greater Toronto and Hamilton}

\section{Area}

This is a Regional Transportation Plan (RTP) to create a common vision for transportation. This plan is proposed under the Greater Toronto Transportation Authority Act Section 6 (2). It will help to revitalize neighbourhoods where residents can take transit, ride a bicycle or walk to fulfill their day's activities, and where children can walk to school. Over 7,000 km of new lanes, trails and pathways for pedestrians and cyclists will make walking and cycling safe and encourage healthy lifestyles. The plan suggested integrated walking and cycling networks for the GTHA which will bring every GTHA urban resident within a maximum of one kilometre of a dedicated bicycling facility. It also proposed a transitioning from free to paid parking to encourage transit and active transportation use. The plan envisions a significant reduction of automobile use as a result, and speculatively, GHG emission per resident will decline, which will result a cleaner air. (Metrolinx, 2012).

The RTP and the Places to Grow Plan have a common interest- both are made to serve GTHA and one of the objectives of the plans is to develop a sustainable transportation plan. The RTP 
aims to achieve a transportation system which is effective, integrated and multimodal, which is also supported by the Places to grow plan.

\subsection{Land-use Planning, Active Transportation and Transit Use:}

Use of alternative mode of transportation to commute, other than private vehicle largely depend on land-use pattern (Mitra \& Buliung, 2011). In order to promote active transportation, planners are now emphasising on walkability. The term walkability indicates the design, accessibility, security of the space which is used by the pedestrians. In order to estimate the walkability of a neighbourhood, different metrics are used which include flow capacity, multimodal connections, sense of place and aesthetics, civic engagement, public health and active living (Lo, 2009). All these metrics are tied to land-use planning.

Land use pattern, density and mix of uses that minimize the length and number of vehicle trips and support current and future use of multimodal transportation system and active transportation. All these issues are prioritized for any development schemes (Ministry of Municipal Affairs, 2014).

In a recent study it has been found that Torontonians have strong preference towards walkable neighbourhood (Toronto Public Health, 2012A). It was revealed that people who live in more walkable neighbourhoods in the GTA use active modes of transportation more often than those who live in auto-oriented neighbourhoods (Toronto Public Health, 2012A). Active transportation is also dependent on accessibility to regional activities and job-housing balance, which significantly reduces vehicular travel. Walkability in particular is closely linked with density, land-use mix, street network, and street network design (Ozbil, 2010; Eriksson et al. 2012). 
Some researchers also include accessibility to public transit as a governing factor for promotion of active transportation (Carr et al. 2010).

\subsection{Energy Consumption by Transportation Modes:}

It is generally conceptualized that if mixed land-use planning can be implemented and appropriate neighbourhood design and planning can be financially supported, then more active transportation can be encouraged which will reduce frequency and length of automobile travelling and lead to less fossil fuel consumption. This will ultimately curb the GHG emission in the atmosphere and support sustainable environment for urban areas (Frank. et.al. 2010)(Figure 2.1). Transportation sector of Canada is the second dominant sector consuming energy and emitting GHG in the atmosphere. Among different modes, Passenger Transportation account for

54 percent of all energy consumption (Natural Resources Canada, 2013). During the period of 1990 to 2010, the total energy consumption for the transportation sector increased 38 percent, from 1,877.9 petajoules (PJ) to 2,595.0 PJ, and associated GHG emissions increased 36 percent, from 131.4 gegatons (Mt) to 179.2 Mt (Natural Resources Canada, 2013). 


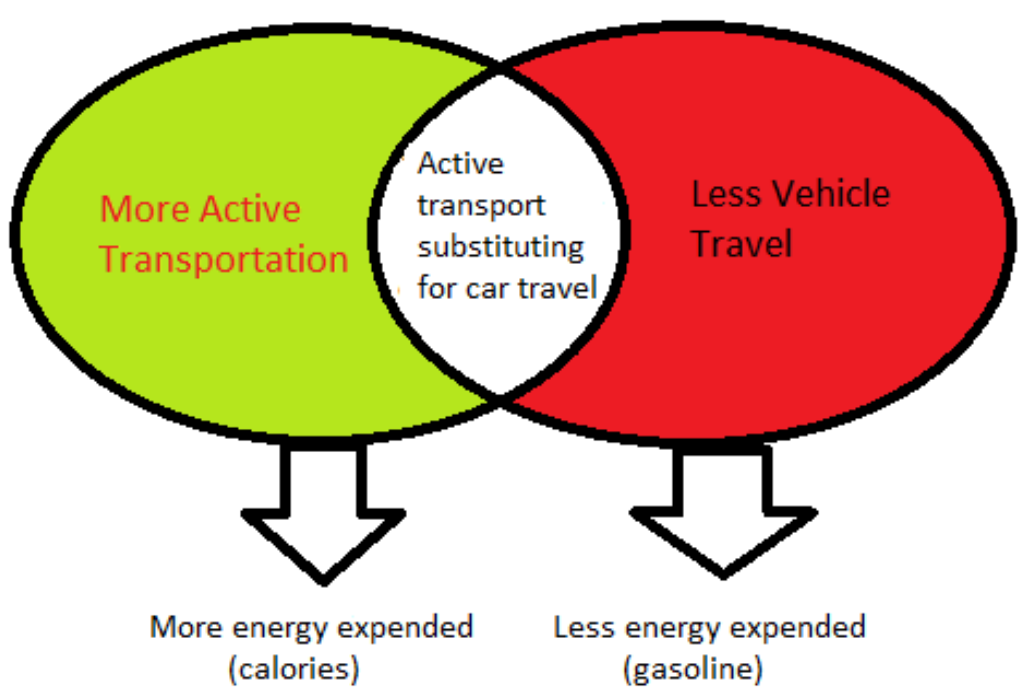

Figure 2.1. Conceptual Transport Energy Model

In 2011, emissions from transportation sector (including passenger, freight, and off-road emissions) were the largest contributor to Canada's GHG emissions, which represented $24 \%$ of overall GHGs (Environment Canada, 2013) . In 2012, $\mathrm{CO}_{2}$ emission constituted 79 percent of total GHG emission which mainly originate from combustion of fossil fuel (Environment Canada, 2013). Emission from Road Transportation rose by 35.8 Mt (37\%) between 1990 and 2012 (Environment Canada, 2013). As vehicles are becoming more fuel efficient, the rate of growth in emissions from Road Transportation has slowed, and emissions from this category have remained stable since 2008. The primary source of this net trend of rising emissions is the increase in the number of passenger-kilometres travelled i.e. more people are driving longer distances (Environment Canada, 2013).

Rail transportation constitutes a major portion of urban transportation in GTHA. Consequently contribute in energy consumption and GHG emission. Compared to automobile travelling, both 
diesel- and electric-powered passenger rail services offer an efficient way of transporting people, with a net reduction in GHG emissions. GO contributes a fraction of the regional GHG emissions and therefore unable to make a notable difference towards climate change, electrifying the entire network could reduce GHG emissions by 319,000 tonnes per year, which will account for approximately $94 \%$ of the total GO Rail's contribution toward GHG emissions. On the other hand faster transit times and the reduction in highway journeys by private car, a further 11,000 tonnes of GHG per year can be saved (Metrolinx, 2013).

Active transportation is considered as a sustainable transportation mode that produces no GHG or other air pollutants. In addition an increase in active transportation will ultimately result less wear and tear of road surface and thereby reduce maintenance cost and resource use. Active transportation is encouraged for short trips and be linked with transit systems to make longer trips (Ontario Professional Planners Institute, 2012). A healthy man of average weight of 175 pounds and healthy woman of 140 pounds can burn 460 calories and 370 calories respectively by walking briskly $(3.5 \mathrm{mph})$ or cycling $(5.5 \mathrm{mph})$ for an hour (Pace, 2000). The short term health benefits of such activity include a healthier heart, improved burning of calories, and increased endurance. The long term benefits include reduced risk of developing diabetes, high blood pressure and heart disease and obesity (Pace, 2000). The environmental benefits are obvious because pedestrians/cyclists do not use fossil fuel and thereby do not directly generate any Greenhouse Gases (EcoPlan, 2012).

The Concept of Carbon Neutral Communities is therefore emerging and drawing attention of policy makers, NGOs, and citizens. A carbon neutral community is any place or neighborhood 
where carbon produced by households through energy use, water use, solid waste, transportation use and high impact food consumption is reduced by taking certain measures resulting in neutral or net zero effect (Sommerhoff, 2003). Australia has taken several planned strategies to reduce its fossil fuel consumption by buildings and transportation- the major consumers of fossil fuel. A carbon neutral community is likely to still produce GHG emission although, almost inevitably, to a lesser degree than the state without any plan to curb the emission (Horne, et.al. 2007).

The ambitious GHG reduction target of City of Toronto within its 2007 Climate Change, Clean Air and Sustainable Energy Action Plan suggests that it will reduce greenhouse gas emissions to 80\% below 1990 levels of 22 million tonnes per year, by 2050. (Toronto Public Health, 2012B). City authorities are taking efforts to attain carbon neutral status to ensure environmental sustainability. It is important to note that there are significant difference between greenhouse neutral and zero emission. The Metropolitan area of Portland, Oregon has successfully reduced $\mathrm{CO}_{2}$ by implementing a strong land-use planning program that promotes compact development within an urban growth boundary which has created an efficient city that is easier to serve with non-automobile transportation modes. Dependable bus service, streetcar and light rail lines, combined with bicycle and pedestrian facility ensure that people who do not drive can take advantage of a variety of other travel options (Bradley and Associates, 2007). Areas with high rates of urban growth, investment in public transport systems and low-carbon infrastructure can avoid dependence on carbon intensive modes and prioritizing infrastructure for pedestrians and integrating non-motorized and transit services can create economic and social co-benefits (International Panel on Climate Change, 2014). 


\section{Chapter Three: Methodology}

The research methodology followed for this study is discussed in the following paragraphs.

\subsection{Justification of Research Topic}

Policy guidelines proposed in the Places to Grow Plan are expected to attract more people and employment opportunities in Growth Centres in GTHA. This will eventually increase commuting for work, school and recreation and other daily needs. The present study aims to explore the impact of policy guideline of intensification and compact and transit supportive development in the growth centres on commuting behaviour of working people ageing 18-65. Number of commuters and distance travelled impact upon the traffic volume on the roads. On the other hand, transportation mode chosen by the people who commute for work and other purposes directly impact environment. On an average Canadian workers have to commute for 26 minutes on regular days and people living in larger metropolitan areas have to travel a longer distance (Turcottee, 2011). For Toronto CMA the average commute time is 32.8 minutes and for Hamilton CMA it is 26.9 minutes (Statistics Canada, 2013). This generates GHG gases in the atmosphere and emission of GHG gases to air resulting from daily commute is a major policy concern. The modal choice is linked with how much energy consumption. Energy burned by motorized vehicles using fossil fuel has a direct impact on environment whereas active transportation users who do not have a direct impact on environment.

The present study will attempt to estimate the nature of energy burned in kilocalorie by motorised vehicles and active transportation mode users in two reference years namely 2001 and 2011. These two years are important because they present the scenario of five year before and after the introduction of Places to Grow Plan. The final aim of the study is to explore the impact 
of intensification and Growth Centre Policy of Places to Grow Plan on change in traffic volume and its environmental impact.

\subsection{Data}

Data on trips are obtained from Transportation Tomorrow Survey (TTS). Data related with travel mode, no of trips, length of trips are derived from TTS data. TTS is the most comprehensive travel survey conducted in Greater Toronto and Hamilton Area. The First TTS was conducted in 1986 which included completed interviews for a $4.2 \%$ random sample of all households in the GTA. After the first survey the Data Management Group was formed at the University of Toronto and was made responsible for management and distribution of TTS data. A small update of the survey was done in 1991. During 1991 survey, the survey area was expanded to include a band approximately one municipality deep surrounding the outer boundary of GTA in order to obtain more complete travel data in the fringe areas of GTHA. New surveys were conducted in 1996, 2001, 2006 and 2011. In 1996, the survey area was expanded to include the Regional Municipalities of Niagara and Waterloo, the counties of Peterborough, Simcoe, Vicoria and Wellington, the Cities of Barrie, Guelph, and Peterborough and the Town of Orangeville. This survey included approximately 115,000 interviews representing a 5\% random selection of households throughout the survey area. 2001 and 2006 survey was a repeat of 1996 survey. 2001 survey included 137,000 completed interviews and the survey area was the same as in 1996 except for the omission of the Regional Municipality of Waterloo and inclusion of City of Orillia and all of the County of Simcoe. 2006 survey included 150,000 completed interviews and the survey area was same as in 2001 with the inclusion of the Regional Municipality of Waterloo, the City of Brantford and the County of Dufferin. 2011 TTS survey included approximately 
160,000 completed interviews and the survey area included a similar survey area as in 2006, with the addition of the County of Brant (Data Management Group, 2013).

\subsection{Data Analysis and Presentation}

Data Source: Transportation Tomorrow Survey provided data on trip lengths by different modes for different years. Data for 2001, 2006 and 2011 have been used for this study. Traffic Assessment Zones (TAZ) of 2001 were selected as the spatial unit of data generation and analysis. Data from 2001, 2006 and 2011 TTS survey was used to explore the trend of mode share, vehicle ownership, Vehicle Kilometre (VKT) travelled by Auto Drivers, GO Rail (only) users, Transit (excluding GO) users, commuters who walk and cycle to work. 2001 TTS and 2011 TTS data were used to make a comparative analysis of average energy used by motorized vehicle users and active transportation users. These two years were selected because they represent a time or situation five year before and after the introduction of Places to Grow Plan. Travel data related to commuters aging 18-65 were retrieved from the TTS database. The data included home to work trips only. Data on TAZs of Toronto, Durham, York, Peel, Halton and Hamilton were taken under consideration only. Expansion Factor was considered while generating the data.

TTS Data provides different trip lengths for each transportation mode. Frequency of data occurrence gradually decreases with increasing length of trip. As such the maximum length considered for this study was the length where cumulative percentage of 95.5 percent of trip occurrence ended. This level was selected since 5 percent of confidence level is valid for any statistical validity. 


\section{Energy Consumption (Per Km) By Different Modes:}

The following section will highlight upon the calculation methods which were used to estimate energy consumption methods (in Kcal) by different travel modes.

(i) Energy consumption by car:

In general, a car requires to run $29 \mathrm{~kW}-\mathrm{hrs} / 100$ mile $=29 \mathrm{~kW}-\mathrm{hrs} / 160.93 \mathrm{~km}=0.18020 \mathrm{~kW}$ $\mathrm{hrs} / \mathrm{km}$

1 kilowatt-hour $=3412.14163 \mathrm{BTU}$

Total BTU used by a car per $1 \mathrm{~km}=0.18020$ x $3412.14163 \mathrm{BTU} / \mathrm{km}=614.86 \mathrm{BTU} / \mathrm{km}$

Then, a car uses 614.86 BTU/km (US Department of Energy, 2014).

(ii) Energy Burning (Per km) By Rail

1 Imperial Gallon $=4.54609$ litre. Then, 1 litre $=0.219969$ Imperial Gallon

Total Train Mile per year $=18960$ mile $=18960 \times 1.60934 \mathrm{~km}=30513 \mathrm{~km}$

Total Diesel Consumption $=50410$ Imp. Gallons $=50410 \times 4.54609$ litre $=229169$ litre

Fuel Consumption Rate $=229169 / 30513$ litre $/ \mathrm{km}=7.51$ litre $/ \mathrm{km}=7.51 \times 0.219969 \mathrm{Imp}$ gallon $/ \mathrm{km}=1.6519 \mathrm{Imp}$. gallon $/ \mathrm{km}$

Generally, One Imp gallon gasoline produces equivalent to 114000 BTU.

Total BTU used by a Rail per $1 \mathrm{~km}=1.6519$ x $114000 \mathrm{BTU} / \mathrm{km}=188316.6 \mathrm{BTU} / \mathrm{km}$

Then, a Rail uses 188316.6 BTU/km (GO Transit, 2010).

(iii) Energy Burning by Bus

In general, a Bus uses 105.89 litre $/ 100 \mathrm{~km}=0.10589$ litre $/ \mathrm{km}=0.10589 \times 0.264172$ gallon $/ \mathrm{km}=$ 0.02797 gallon $/ \mathrm{km}$

Here, 1 Litre $=0.264172$ gallon

One gallon gasoline produces equivalent to 114000 BTU.

Total BTU used by a Bus per $1 \mathrm{~km}=0.02797 \times 114000 \mathrm{BTU} / \mathrm{km}=3189 \mathrm{BTU} / \mathrm{km}$ 
Then, a Bus uses $3189 \mathrm{BTU} / \mathrm{km}$

(Wolfarm, 2014. ; National Service Centre for Environmental Publications, 2014).

(iv) Energy Burning (Per km) By Active Transportation

Walking briskly (3.5 mph): Calories burned per hour by Men (Healthy Man) 175 Pounds

$=460$ Calories. By Woman (Healthy Woman) 140 Pounds =370 Calories .

Cycling briskly (5.5 mph) Calories burned per hour by Men (Healthy Man) 175 Pounds

$=460$ Calories. By Woman (Healthy Woman) 140 Pounds =370 Calories .

Average Calories burned by men and woman $=73.71$ calories $/ \mathrm{km}$ (Pace, 2000).

(v) Calculation of Energy Consumption by Different Modes

Average energy consumed by Auto Drivers, Go Rail users, Transit (excluding GO Rail) users were derived by using Transportation Tomorrow Survey and energy burning standards described in the previous section. Similar data was generated for walking and cycling. Data on Auto Driver, Go Rail and Transit users were grouped together to represent average energy consumption by commuters using motorised vehicles. Similar procedure was followed for walking and cycling which were grouped together as active transportation.

\section{Energy Consumption for Car}

Step 1. One car uses 614.86 BTU/KM

Step 2. Total Energy consumed (in BTU) in a TAZ= Total VKT X 614BTU/km

Step 3. 1 BTU=0.252164401 kilocalories

Step 4. Total Kilocalories burned in a TAZ= Total Energy Burned in a TAZ X $\quad 0.252164401$ kilocalories 


\section{Energy Consumption for GO Train}

Step 1. GO Rail consumes 188316.6BTU/KM

Step 2. Total Energy consumed (in BTU) in a TAZ= Total VKT X188316.6BTU/KM

Step 3. 1 BTU= 0.252164401 kilocalories

Step 4. Total Kilocalories burned in a TAZ= Total Energy Burned in a TAZ by GO Rail X 0.252164401 kilocalories

\section{Energy Consumption by Transit excluding GO}

Step 1. A Bus consumes 3189 BTU/KM

Step 2. Total Energy consumed (in BTU) in a TAZ= Total VKT 3189 BTU/KM

Step 3. 1 BTU= 0.252164401 kilocalories

Step 4. Total Kilocalories burned in a TAZ $=$ Total Energy Burned in a TAZ by Bus $\mathrm{X}$ 0.252164401 kilocalories

(vi) Map Preparation

Maps were prepared on Average Energy Consumption by Motorized Transportation and Active Transportation for the year 2001 and 2011. These two years were chosen to evaluate the impact of Places to Grow Plan which was introduced in 2006. The two reference years represent scenarios 5 year before and after the plan. Average data were categorized into four groupseach representing 25 percentile of the distribution. Visual analysis of the distribution of top and bottom percentile for two reference years have been used to describe the effect of the plan in 
GTHA. Any change of top 25 percentile group by motorized vehicles would indicate positive or negative change in energy use and GHG emission from 2001 to 2011. Similar approach is followed for active mode of transportation. A map of Growth Centres, as proposed in the Places to Grow Plan was superimposed on the 2011 map of Average Energy Consumption by Motorised Vehicles to explore the areas where changes are occurring.

\subsection{Limitations}

This research has several limitations. There are different standers for energy consumption for different modes. There is no compiled source/ reference where a consolidated and standardized baseline data is available for energy consumption and carbon emission. Aforementioned data sources were used to calculate energy consumption by motorized vehicles and active transportation. In addition, in an ideal situation the method applied in this research could lead to the calculation of an Energy Index which would be a ratio of energy consumed by active transportation versus energy used by motorized transportation. Since TTS does not provide individual travel data and the trip lengths are provided as straight line trip length, such index could not be developed. 


\section{Chapter Four: Findings}

\subsection{Energy Consumption in GTHA}

The present section will highlight upon the travel behaviour of work commuters living in GTHA to explore the nature of mode share and finally discuss on average energy consumption by motorized and active transportation mode users. A comparative study of 2001 and 2011 will shed light on the impact of intensification of residential and employment facilities in the Growth Centre within GTHA.

\subsection{Mode Share}

Personal automobile users are the most dominant group in all three reference years. The proportion of automobile users shows an increasing trend of growth between 2001 to 2011. Proportion of Transit users significantly increased from 2001 to 2011. In 200124.34 percent commuters used transit excluding GO Rail which was 36.25 and 35.02 in 2006 and 2011 respectively. Commuting using Walking and Cycling is a less popular option. In 2001 only 6.48 percent commuters used walking and cycling to commute to work which was 8.13 percent in 2006 and 8.42 percent in 2011(Figure 4.1).

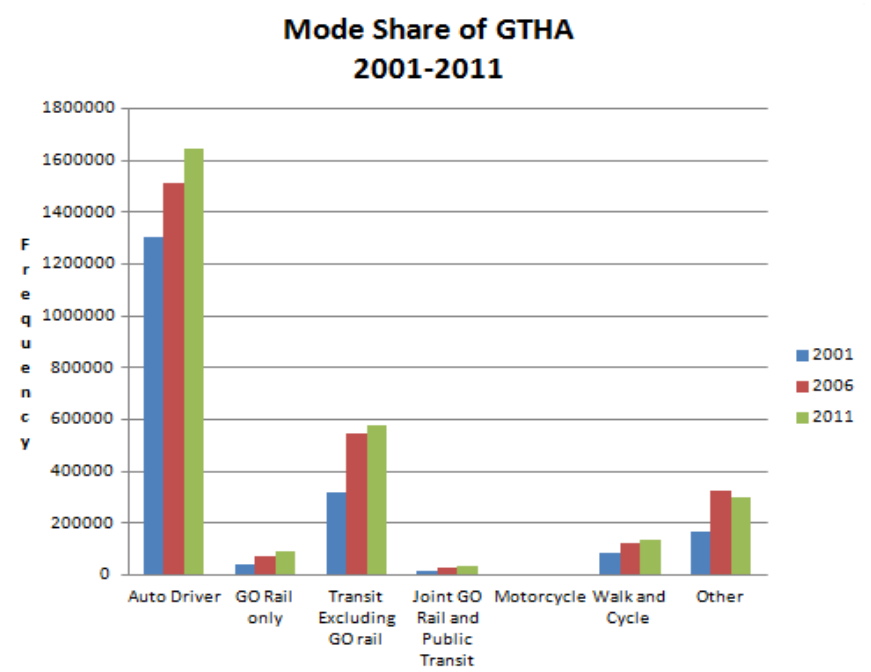

Figure 4.1 Mode Share in GTHA 


\subsection{Vehicle Ownership in GTHA}

Ownership of two cars is common in all areas in all three reference years, except Toronto where households with one car are more dominant. Households with no cars are dominant in Toronto and Hamilton. Other areas show varying degree of proportional dominance.
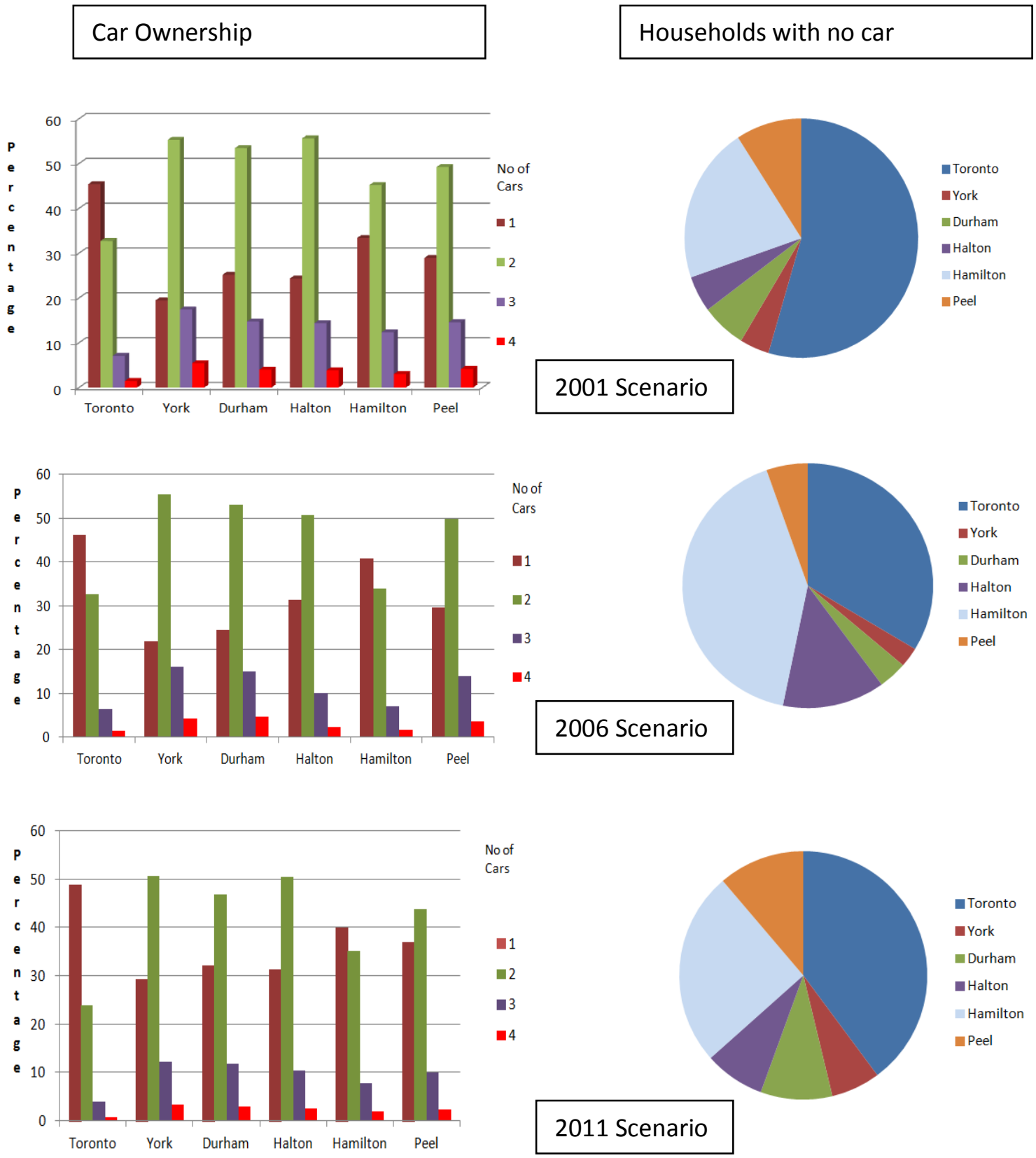

Figure. 4.2. Vehicle Ownership Trend 
Ownership of car is important because these households have to depend on other modes to Commute.

\subsection{Vehicle Kilometer Travelled by Various Travel Modes 4.4.1 Commuting by Personal Automobiles}

Commuters who commute to work in personal vehicles as Auto Drivers are the most dominant group in GTHA in three reference years. Total length of trips (in KM) increased 3.85 percent in 2006 from 2001 and in 2011 it increased only 0.42 percent from the 2006 level. The average length (Total VKT/ Total Population) of trips remained almost the same. Region of Peel, York and Halton show significant growth in travel during 2001-2006 period which slowed down during 2006-2011 period (Table 4.1). During both the periods Toronto shows negative growth. Highest negative growth occurred in Durham. Neighbourhoods of Toronto shows gradual decrease of total VKT by the commuters who travel as Auto Drivers (Figure 4.3). Auto dependency has increased in York and Peel region from the 2001 and 2006 levels. In Hamilton, Halton and Durham area, auto commuters have more or less stabilized.

Table 4.1. Growth of VKT by Auto Drivers

\begin{tabular}{lcc}
\hline \hline Area & $2001-2006$ & $2006-2011$ \\
\hline Toronto & -8.34 & -2.76 \\
Durham & 7.45 & -8.27 \\
York & 10.79 & 5.58 \\
Peel & 7.95 & 2.84 \\
Halton & 12.52 & 2.22 \\
Hamilton & -3.27 & 0.64 \\
\hline \hline
\end{tabular}




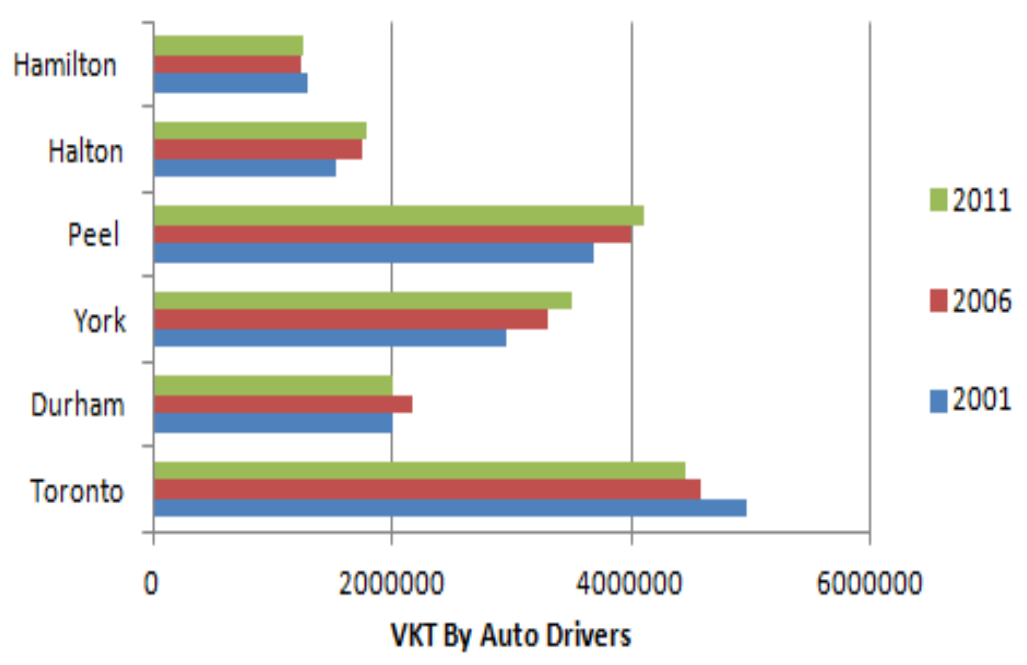

Figure 4.3. Changes in Total VKT of Auto Drivers

\subsubsection{Commuting by GO Rail only}

Commuting by GO Rail play a significant role in Halton, Peel, York and Durham region. Though Toronto experienced about 20 percent growth, still Go rail is not a dominant mode there. Durham, York and Halton experienced significant growth of total VKT (Table 4.3). Highest number of commuters commutes from York region by GO Rail. Although Hamilton show the highest growth of commuters but the total number of commuters is very low from Hamilton. Total ridership in GO Rail has increased but different scenario is evident in different regions (Figure 4.4). York and Halton experienced highest change. Total VKT increased from 165326 to 468420 representing 64.71 percent increase in York and from 275946 to 441721 representing 37.53 percent increase in Halton. 
Table 4.2. Growth Trend of VKT by GO Rail Only

\begin{tabular}{lcc}
\hline \hline Area & $2001-2006$ & $2006-2011$ \\
\hline \hline Toronto & 8.31 & 20.34 \\
Durham & -10.39 & 32.01 \\
York & 36.50 & 44.42 \\
Peel & 12.90 & 15.29 \\
Halton & 1.89 & 36.32 \\
Hamilton & -569.78 & 67.53 \\
\hline \hline
\end{tabular}

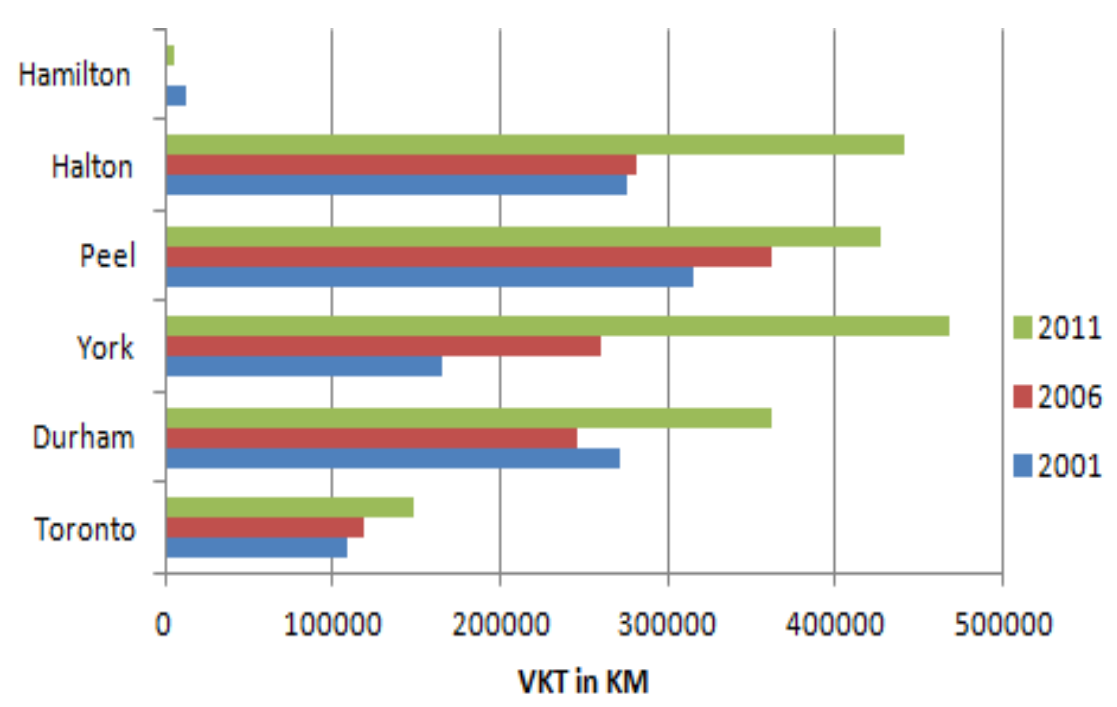

Figure 4.4. VKT change for GO Rail only

\subsubsection{Commuting by Transit Excluding GO}

It is interesting to notice that transit users of Toronto have exacerbated the transit users in other regions (Figure 4.5). People living in Peel and York region also commute by transit excluding GO though the proportion is comparatively less that Toronto. VKT by this mode was 21, 41,932 
in 2001 in Toronto which grew to 24, 49,525 in 2011 representing 12.51 percent increase. Commuters using transit have decreased considerably in Hamilton which experienced a negative growth. Only Toronto and Halton shows increasing growth. Durham, Peel and York have experienced decreasing growth during 2006-2011 than 2001-2006 periods (Table 4.3).

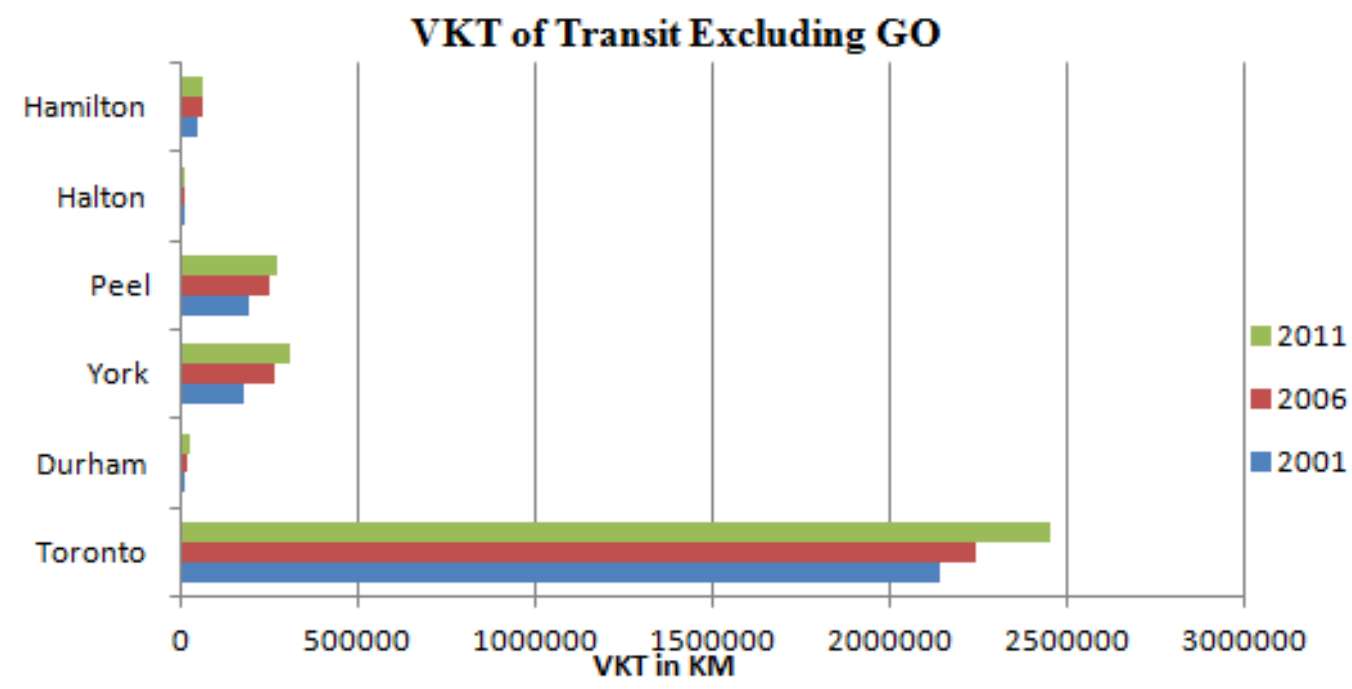

Figure 4.5. VKT change for Transit excluding GO Rail

Table 4.3. Growth Trend VKT of Transit excluding GO

\begin{tabular}{lcc}
\hline \hline Area & $2001-2006$ & $2006-2011$ \\
\hline \hline Toronto & 4.50 & 8.44 \\
Durham & 34.13 & 23.22 \\
York & 33.10 & 14.65 \\
Peel & 23.95 & 7.38 \\
Halton & 14.47 & 18.48 \\
Hamilton & 18.92 & -0.09 \\
\hline \hline
\end{tabular}




\subsection{Commuting by Waking and Cycling}

Active transportation mode which predominantly include walking and biking is an option of commuting. Although only a limited part of work commute in GTHA is done through this modal option. Toronto Region experienced significant increase of active mode share for work commute (Figure 4.6). Significant difference is evident in the growth rate of this mode share during 20012006 and 2006-2011 periods (Table 4.4).

Table 4.4. Growth Trend of Active Transportation in GTHA

\begin{tabular}{lcccc}
\hline \hline Area & \multicolumn{2}{c}{ Walk } & \multicolumn{2}{c}{ Cycle } \\
\hline \hline & $2001-2006$ & $2006-2011$ & $2001-2006$ & $2006-2011$ \\
Toronto & -8.92 & 16.41 & -0.40 & 47.20 \\
Durham & -2.62 & -2.50 & 17.57 & 11.44 \\
York & 4.28 & 11.30 & 22.31 & 63.21 \\
Peel & 4.86 & 19.89 & 12.21 & 44.00 \\
Halton & 12.07 & 18.08 & -41.53 & 53.00 \\
Hamilton & -16.57 & -3.88 & 4.26 & -5.92 \\
\hline \hline
\end{tabular}

Significant growth occurred in commuting by walking and cycling during 200-2011 period. Toronto experienced 16.41 percent growth for commuters who walk during 2006-2011 period from - 8.92 percent growth during 2001-2006 period. For cyclists, Toronto had 47 percent growth for 2006-2011 period which was only -0.40 percent during 2001-2006 period. York and Peel region also experienced similar growth in active transportation during 2006-2011 period. 
Highest length of commuting by walking and cycling occurs in Toronto. Total number of people who walked and biked to workplace in 2011 was 64766 and 73165. The lowest figures occur in the case of Halton where the corresponding numbers are 3540 and 1419 only (Figure 4.4). Although the figures are comparatively less, still considerable length was commuted by walking and cycling in Peel and Hamilton (Figure 4.6).

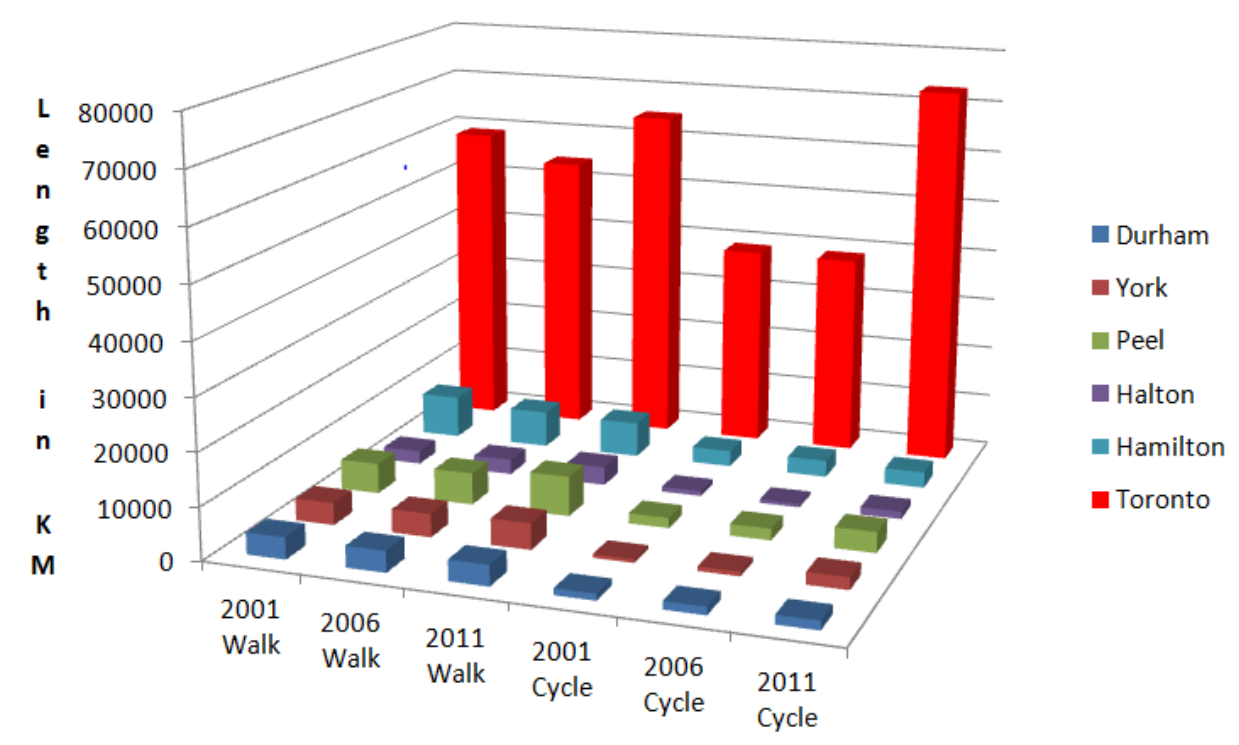

Figure 4.6. Increase of Active Transportation (KM Travelled)

\subsection{Average Energy Use by Motorized Vehicles (in BTU and Kilocalories)}

The energy consumption pattern of different transportation modes is different. Since personal automobile, GO Rail and transit excluding GO are the most dominant modes in GTHA, the current section will highlight upon the combined energy consumption of these three modes for motorized vehicle and calories burned by active transportation (walking and cycling). Figure 4.7. shows the distribution pattern of fossil fuel burned by motorized vehicles in 2001 and Figure 4.8. shows the same for the year 2011. Average energy consumption by the commuters are presented in kilocalories. These two reference years are chosen because they represent the situations 5 
years before and after the implementation of the Places to Grow Plan. The maps indicate a growth trend of top 25 percentile of the energy consumers, namely fossil fuel in certain areas. Significant decrease is noticed for top 25 percent energy users in Caledon area between 2001 and 2011. Large increase in top 25 percentile group is noticed in York and Durham region. In both the scenarios Toronto remained as the 50-75 percentile group. Significant expansion of top 25 percentile area is noticed in specific areas. The top 25 percentile areas in 2011 are mostly located around the areas which are identified as future growth centres in the GTHA Growth Plan (Figure 4.9). Perhaps increase of population in the Growth centres has influenced the growth of commuters using motorized modes in these growth centres. If the Growth Centres continue to attract more people and employment opportunity then, it can be easily anticipated that TAZs around these growth centres would generate more trips which may lead to more GHG emission through travelling. It should be noted here that data on trip origin attached to a TAZ are only presented here. Trip Data related with TAZs as destinations will definitely produce more complicated scenario.

Interesting change is noticed for energy consumed by motorized vehicles. Several large TAZs in Caledon belonging to top 25 percentile category in 2001 transferred to $50-75$ or $25-50$ percentile group. Which indicate a modal shift. On the other hand, small as well as large TAZs located in Durham and York region which are also located along a belt of Growth Centres have shifted to top 25 percentile group. TAZs located around Ajax, Whitby and Oshawa downtown have transformed to top 25 percentile group in 2011 from a lower percentile group of 2001. In 2001 almost entire Toronto belonged to 50-75 percentile group. In 2011, TAZs located at downtown and adjacent areas shifted to $25-50$ percentile group, indicating a modal shift to more greener travel option. 


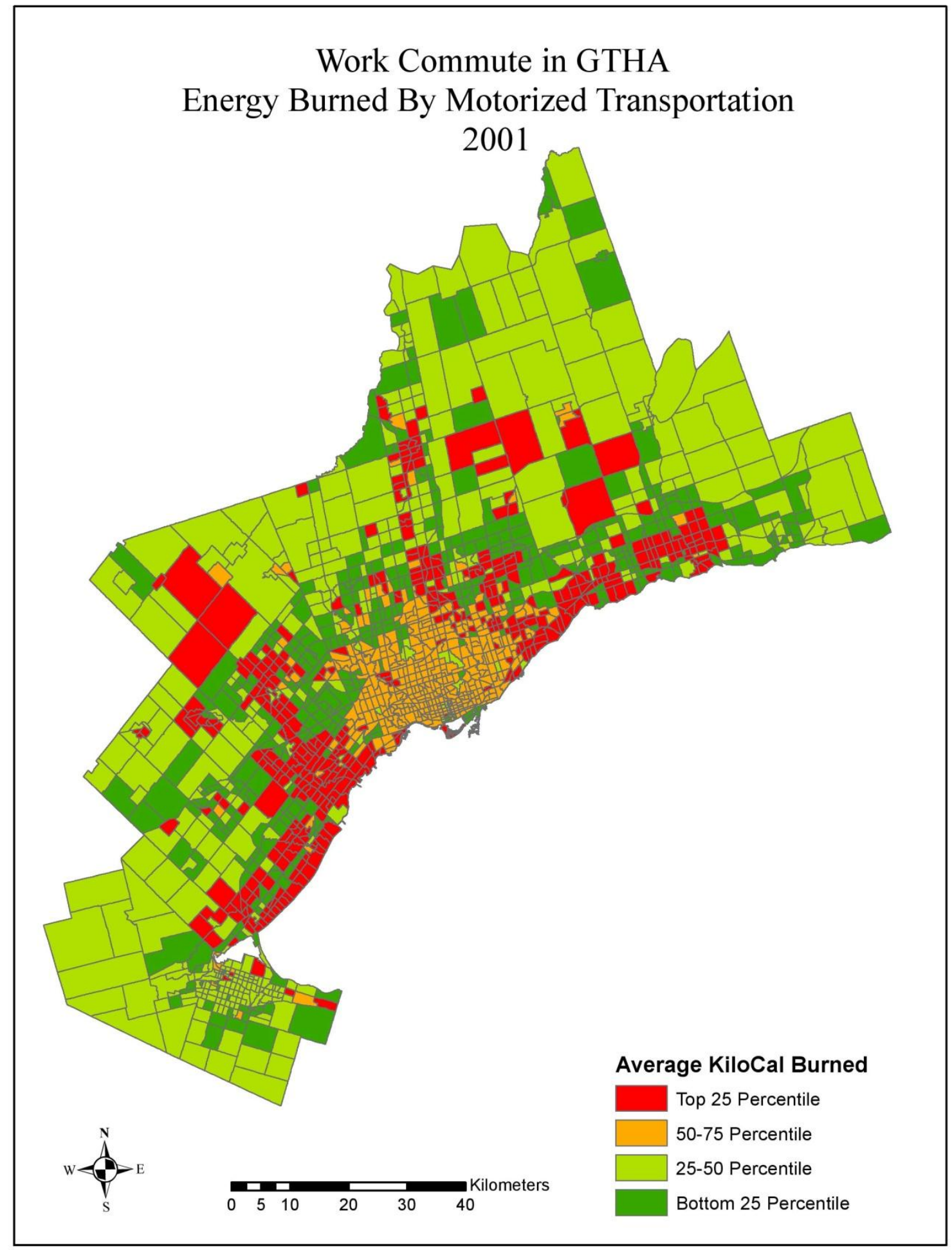

Figure 4.7 Energy burned by Motorized Vehicles in 2001 


\section{Work Commuters in GTHA Average KiloCal Burned By Motorized Vehicles 2011}

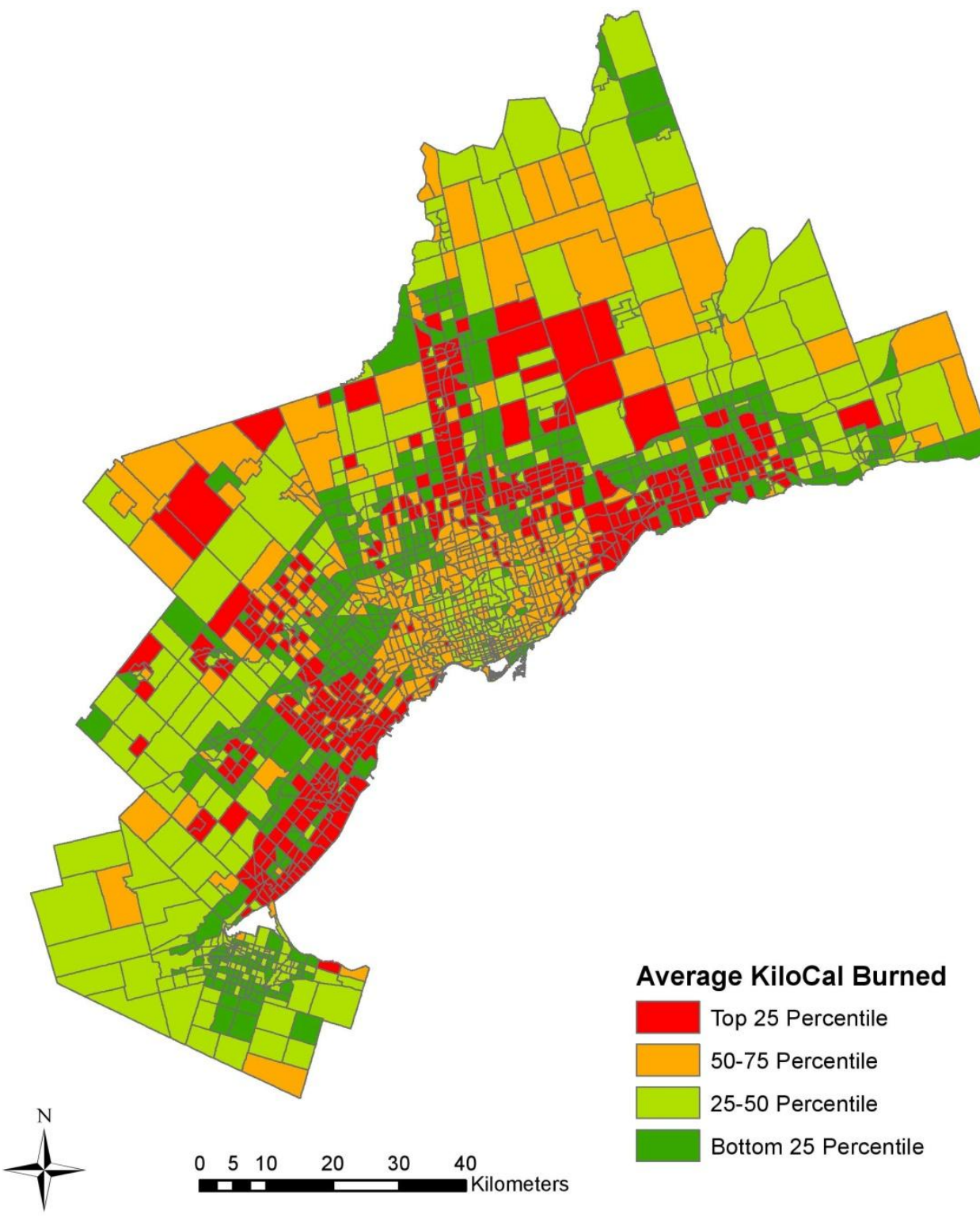

Figure 4.8 Energy burned by Motorized Vehicles in 2011 


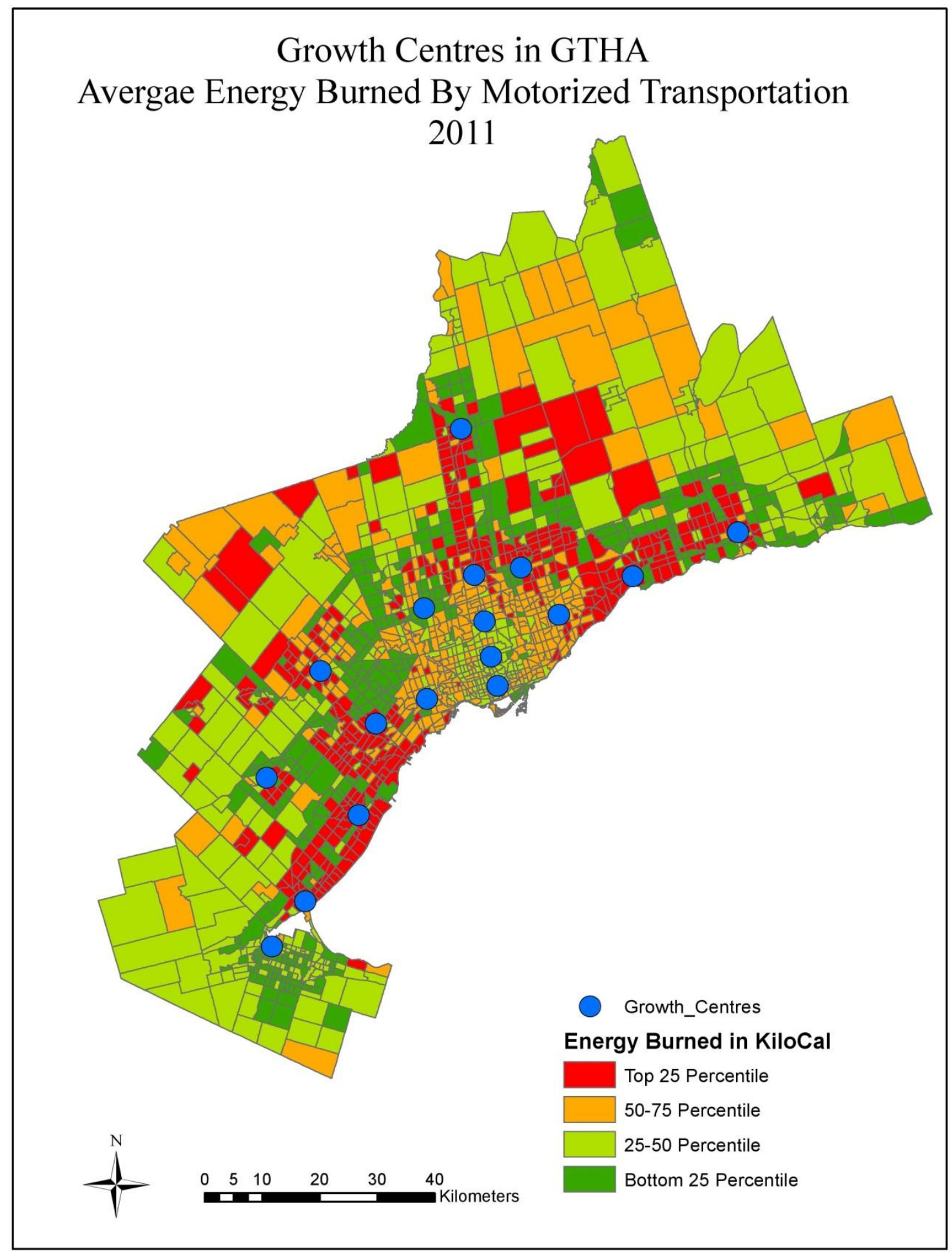

Figure 4.9 Growth Centres and Energy burned by Motorized Vehicles in 2011 


\subsection{Energy Consumption by Active Transportation Modes}

Active transportation modes namely walking and cycling are considered to be green mode as they do not burn fossil fuel. Rather they burn energy from body fat which has certain health benefits. Figure 4.10 and 4.11 show the average energy use pattern of active transportation mode in the GTHA for the year 2001 and 2011. Areas located near Downtown Toronto, Mississauga, Oakville and Brampton and Hamilton seem to be more active transportation dependent for both reference years. Major concentration of this category is found in Toronto where concentration of Growth Centres is high. Some top 25 percentile areas of 2001 transferred to 50-75 percentile category in 2011. Some bottom 25 percentile areas transformed to $25-50$ percentile group in 2011. The latter trend is a good indication of development of active transportation mode share in GTHA. 


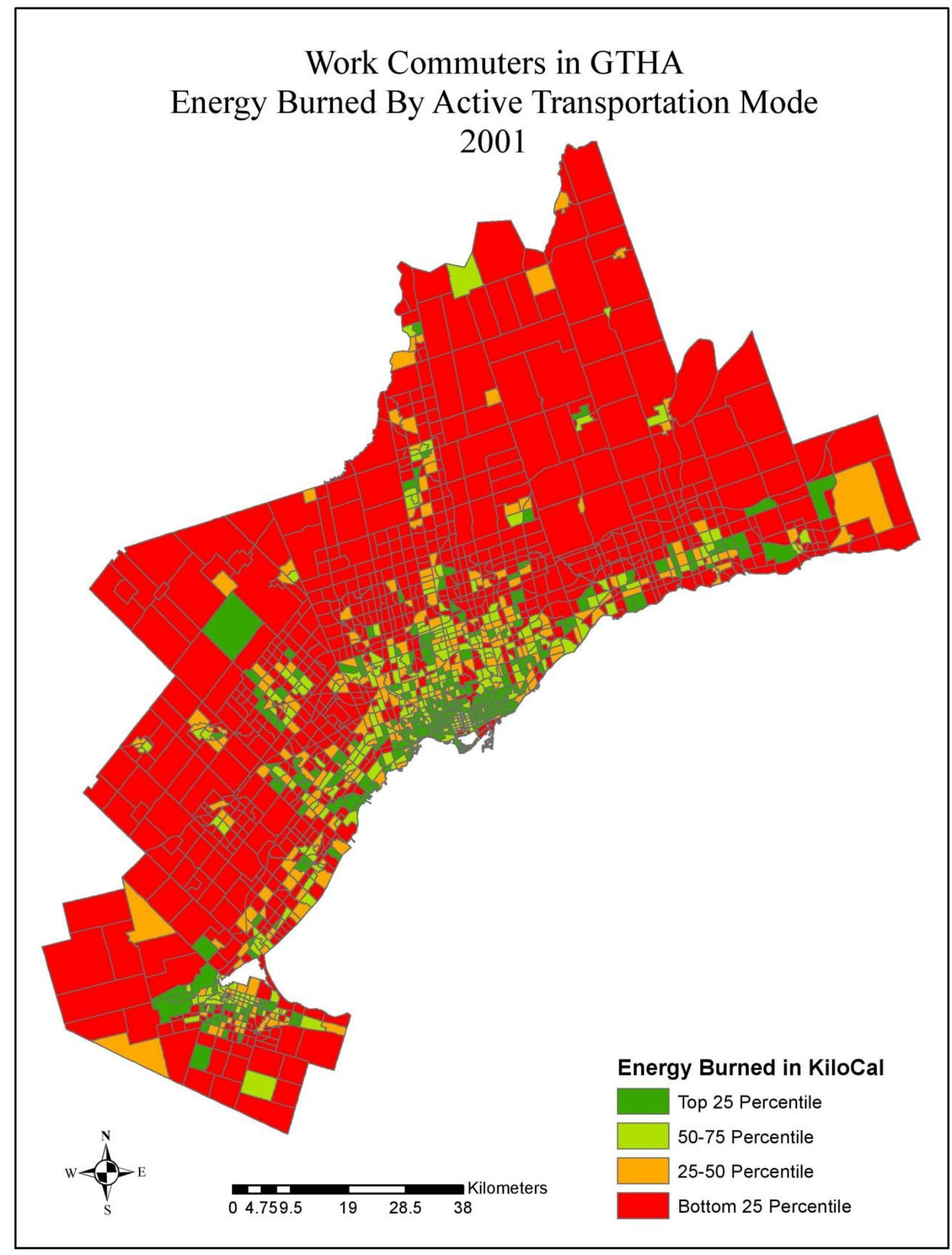

Figure 4.10. Energy burned by Active Transportation in 2001 


\section{Work Commuters in GTHA \\ Average KiloCal Burned By Active Transportation Mode}

2011

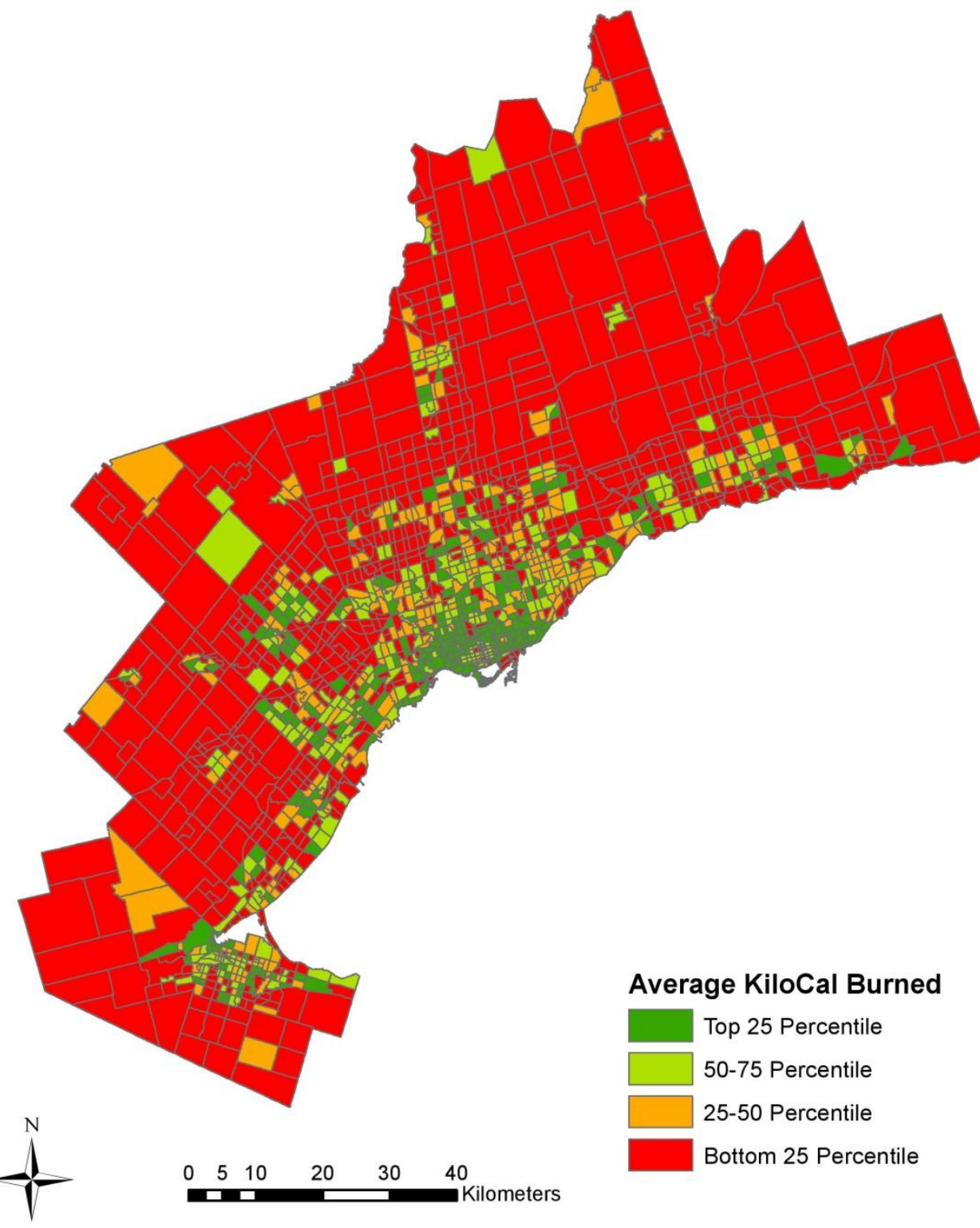

Figure 4.11. Energy burned by Active Transportation in 2011 


\subsection{Growth Plan for GTHA and Average Energy Consumption}

The Places to Grow Plan of GTHA suggests that growth will be managed through directing new growth in built-up areas by intensification. The plan also emphasise on reducing dependence on the automobile through the development of mixed-use, transit-supportive, pedestrian-friendly urban environments which will likely provide convenient access to intra- and inter-city transit. Priority is given to plans and investments to ensure a balance of jobs and housing in communities across GTHA to reduce the need for long distance commuting and to increase the modal share for transit, walking and cycling (Ontario Ministry of Infrastructure, 2013).

After 5 years of implementation of the Growth Plan, TAZs located in and around Growth centres have started generating more and/or longer automobile trips (including cars and all forms of transit) as indicated by the increase of energy usage by motorized vehicles (Figure 4.5 and 4.6). If this trend continues in future, the TAZs located in and around Growth centres will use more fossil fuel and generate more GHG in the atmosphere. The intensification strategy of Places to Grow Plan could not reduce energy consumption and associated GHG emission in its first five years of implementation.

Work commute by walking and cycling concentrate in the main urban areas. They are also the places located within close vicinity of Growth Centres. TAZs located in the sub-urban areas do not show much participation in commuting by active transportation and as such mainly belong to the bottom 25 percentile group in 2001 and 2011. This indicates that implementation of the Places to Grow plan could not bring significant positive change to active transportation which is also linked with transit ridership. 
The Places to Grow Plan was introduced in 2006. The intensification strategy of the plan is embedded with municipal plans and regional transportations plans of the region now. The discussion presented in previous sections indicates that a noteworthy change has taken place around the Growth Centres which are mainly the Downtowns of the Urban Areas located within the GTHA. Growth Centres and places around the Growth Centres demonstrate considerable increase of motorized energy consumption which is an indication of more GHG emission. Despite the increase in the active transportation modes, sustainability of the transportation system could not be properly implemented which is apparent from the maps shown here. 


\section{Summary and Conclusion}

The Places to Grow Plan was introduced in 2006 to guide the development and growth of urban and suburban areas in GTHA. After five years of its introduction, the region has started enjoying the positive and negative impacts of this plan.

Concentration of urban facilities and jobs in the growth centres within GTHA generate intra and inter urban movements. People commute for work and various other purposes. The current study focused on work commute only. Data generated by TTS has been used to understand the nature of work commute in GTHA. Two reference years namely 2001 and 2011 signifying the status of GTHA five years before and after implementation of the plan, were chosen to understand the influence of the Growth Plan on work commute and associated urban facilities. Data were analyzed at the scale of TAZs of residence within the GTHA. The ultimate goal was to explore average energy consumption pattern of motorized trips (which include automobile, GO Rail and Transit excluding GO) and trips made by active transportation (which include walking and cycling).

Variations are observed in these two types of modal choices in between five years before and after implementation of the plan. It has been revealed through the study that personal vehicle is the most dominant mode of transportation used to commute for work. Auto dependency has increased in York and Durham regions. Toronto has experienced gradual decrease in this regard from 2001 and 2006 standards. With regards to the GO Rail users, Halton, Peel, York and Durham show growing trend. Hamilton show a significant decline and Toronto show moderate 
increase of commuters using this mode. Work commuters in Toronto using transit has enormously increased from the year 2001 and 2006. Peel and York also show some positive change in this mode share.

Active transportation mode use is most dominant in Toronto. Other areas show some positive trend but not as extensive as Toronto. During 2006-2011 period several municipal plans and policies were taken to increase the modal share of Active Transportation. These include Places to Grow Plan, Provincial Policy Statement, 2005, The Big Move: Regional Transportation Plan for GTHA and others. Bike facilities are being developed to facilitate biking in Toronto and adjacent areas in order to ensure safe commuting by cycle.

Energy used by motorized vehicles show some interesting change between the period of five year before and after the implementation of Places to Grow Plan. Some top 25 percentile areas in located in Mississauga, Brampton and Milton area have shifted to lower percentile group in between 2001 to 2011, which is an indicative of modal shift to more sustainable travel options. On the other hand, new areas have been added to top 25 percentile group in 2011 located in Ajax, Whitby and Oshawa. Similar trend is observed in York.

An increase of motorized work commuters and energy consumption by them is noticed around the growth centres. TAZs located away from growth centres show less amount of energy consumption by motorized vehicles. A significant shift to active mode of transportation is 
noticed in 2011. Regional Municipality of Toronto, Mississauga, Oakville and Brampton are more dominated by active transportation.

The Places to Grow Plan of GTHA will lead to more population and job concentration in the growth centres located within GTHA. If the current trend of modal choice continues then it would lead to more fossil fuel use and energy burning in and around growth centres which will create negative impact on the atmosphere and human health. Results from this study the need for more emphasis on infrastructure and financial support for the promotion of active transportation and transit. Clearly defined and designed plan for transit supportive and active transportation based urban development will be the best way to curb the future fossil fuel consumption needs for work commute and purposes for trip making in GTHA. 


\section{Bibliography}

Bradley, M.J. \& Associates. (2007). Comparison of energy use \& $\mathrm{CO}_{2}$ emissions from different transportation modes. American Bus Association, Retrieved from http://www.buses.org/files/ComparativeEnergy.pdf.

Buliung, R. N., Raktim, M., \& Faulkner, G. (2009). Active school transportation in the Greater Toronto Area, Canada: An exploration of trends in space and time (1986-2006). Preventive Medicine, 48(6), 507-512.

Carr, L. J., Dunsiger, S. I. \& Marcus, B. H. (2010). Walk score as a global estimate of neighborhood walkability. American Journal of Preventive Medicine, 39 (5), 460-463.

City of Toronto.(2010). Toronto official plan. City of Toronto. Retrieved from http://www1.toronto.ca/static_files/CityPlanning/PDF/chapters1_5_dec2010.pdf.

Data Management Group. (2013). Transportation tomorrow survey. Retrieved from http://www.dmg.utoronto.ca/transportationtomorrowsurvey/index.html

Environment Canada. (2013). Canada's emissions trends. Environment Canada. Retrieved from http://www.ec.gc.ca/ges-ghg/985F05FB-4744-4269-8C1AD443F8A86814/1001-Canada's\%20Emissions\%20Trends\%202013_e.pdf.

EnviroStats: Canada's growing population and its environmental influence, 1956 to 2006. (n.d.). Statistics Canada. Retrieved June 26, 2014, from, http://www.statcan.gc.ca/pub/16-002x/2007001/article/10177-eng.htm.

Eriksson, Ulf, Arvidsson, D., Gebel, K. Ohlsson, H.\& Sundquist, K.(2012). Walkability parameters, active transportation and objective physical activity: moderating and mediating effects of motor vehicle ownership in a cross-sectional study. International Journal of Behavioral Nutrition and Physical Activity, 9 (123), 1-10. 
Frank, L. D., Greenwald, M. J., Winkelman, S., Chapman, J. \& Kavage S. (2010). Carbonless footprints: Promoting health and climate stabilization through active transportation. Preventive Medicine 50, 99-105

Frank, L. D., Sallis, J. F,, Conway, T. L., Chapman, J. E., Saelens, B. E. \& Bachman, W. (2006). Many pathways from land use to health: Associations between neighborhood walkability and active transportation, body mass index, and air quality. Journal of the American Planning Association, 72 (1), 75-87

Government of Ontario. Ministry of Finace. (2011). National household survey highlights: Factsheet 5. (n.d.). 2011 National Household Survey Highlights. Retrieved from http://www.fin.gov.on.ca/en/economy/demographics/census/nhshi11-5.html.

Government of Ontario. Ministry of Municipal Affairs and Housing. (2005). Provincial policy statement. Retrieved from http://www.mah.gov.on.ca/Page1485.aspx.

Government of Ontario. (2014). Ministry of Municipal Affairs and Housing. Provincial policy statement: Under the planning cct. (n.d.). Retrieved from http://www.mah.gov.on.ca/AssetFactory.aspx?did=10463.

GO Transit. (2010). Electrification study. Retrieved from http://www.gotransit.com/electrification/en/current_study/Appendix20Files/Appendix205 .$p d f$

Government of Canada, Environment Canada. National inventory report: Greenhouse gases and sinks in Canada 1990-2012, Executive Summary. (n.d.). Retrieved from https://www.ec.gc.ca/ges-ghg/default.asp?lang=En\&n=3808457C-1.

Grabow, M.L., Spak, S. N., Holloway, T., Stone, Jr. B., Mednick, A.C. \& Patz, J.A. (2012). Air 
quality and exercise-related health benefits from reduced car travel in the midwestern United States. Environmental Health Perspectives, 120(1), 1-76.

Horne, R. E., Bates, M., Fien, J., Kellett, J. \& Hamnett, S. (2007). Carbon neutral communities: Definitions and prospects. Centre for Design, RMIT University and University of South Australia. Retrieved from http://mams.rmit.edu.au/4m5iz8pii1ts1.pdf.

Intergovernmental Panel of Climate Change. (2014). Climate change 2014. Mitigation of climate change: Summary for policy makers. Retrieved from http://www.ipcc.ch/

Lo, R. H. (2009). Walkability: what is it? Journal of Urbanism, 2 (2), 145-166.

Metrolinx. (2008). The big move transforming transportation in the Greater Toronto and Hamilton area. Toronto, Ont. Retrieved from http://www.metrolinx.com/en/docs/pdf/board_agenda/20080926/PP08-013DraftRTPAppendixA.pdf

Mitra, R., \& Buliung, R. N. (2012). Built environment correlates of active school transportation: Neighborhood and the modifiable areal unit problem. Journal of Transport Geography, 20(1), 51-61.

Mitra, R. (2013). Independent mobility and mode choice for school transportation: A review and framework for future research. Transport Reviews, 33(1), 21-43.

Ministry of Municipal Affairs and Housing. (2014). Provincial policy statement under planning act. Retrieved from http://www.mah.gov.on.ca/Page186.aspx

Ministry of Economic Development, Employment and Infrastructure. (2006). Places to growgrowth plan for the Greater Golden Horseshoe. Retrieved from https://www.placestogrow.ca/index.php?option=com_content\&task=view\&id=9\&Itemid $\equiv 14$ 
Morse, J. M. (1994). Critical issues in qualitative research methods. Thousand Oaks: Sage Publications.

National Service Center for Environmental Publications. (2014). Retrieved from http://nepis.epa.gov/Exe/ZyNET.exe/P100B3FL.TXT?ZyActionD=ZyDocument\&Client= $\underline{\text { EPA \&Index }=1995+\text { Thru }+1999 \& \text { Docs }=\& \text { Query }=\& \text { Time }=\& \text { EndTime }=\& \text { SearchMethod }}$ $=1 \&$ TocRestrict $=n \&$ Toc $=\&$ TocEntry $=\& Q$ Field

Ozbil , A. N. (2010). Walking to the station: The effects of street connectivity on walkability and access to transit. Unpublished dissertation presented to the academic faculty In partial fulfillment of the requirements for the degree Doctor of Philosophy in the College of Architecture, Georgia Institute of Technology, Georgia, USA.

Pace, B. (2000). The benefits of regular physical activity. The Journal of the American Medical Asscoaition, 283, 22

Perotta, K., Campbell, M., Chirrey, S., Frank, L., \& Chapman, J. (2012). The walkable city neighbourhood design and preferences, travel choices and health. Toronto, Ont.: Toronto Public Health. Retrieved from http://www.toronto.ca/health/hphe/pdf/walkable_city.pdf

Pope, C., \& Mays, N. (1995). Qualitative research: Reaching the parts other methods cannot reach: an introduction to qualitative methods in health and health services research. $B M J$, 311(6996), 42-45.

Public Health Agency of Canada. (2010). What is active transportation? (n.d.). Retrieved from http://www.phac-aspc.gc.ca/hp-ps/hl-mvs/pa-ap/at-ta-eng.php.

Sperling, D. \& Spencer, J.C. (2009). Reducing climate impacts in the transportation sector. Proceedings of the 11th Biennial Asilomar Transportation and Energy conference held in August 2007.

Speziale, H. J., \& Carpenter, D. R. (2002). Qualitative research in nursing: advancing the 
humanistic perspective (3rd ed.). Philadelphia, Pa.: Lippincott Williams \& Wilkins. Sommerhoff, Emilie W. (2003). Carbon neutral neighbourhood. Architecture, 92 (4), 87-89. Toronto Public Health. (2012A). The walkable city: Neighbourhood design and preferences, travel choices and health. City of Toronto. Retrieved from http://www.toronto.ca/health/hphe/pdf/roadtohealth.pdf.

Toronto Public Health. (2012). Road to health, improving walking and cycling in Toronto. City of Toronto. Retrieved from http://www.toronto.ca/health/hphe/pdf/roadtohealth.pdf.

Turcotte, M. (2011).Commuting to work: Results of the 2010 General social survey. Component of Statistics Canada Catalogue no. 11-008-X. Canadian Social Trends. Retrieved July from http://www.statcan.gc.ca/pub/11-008-x/2011002/article/11531eng.pdf.

US Department of Energy. (2014). Fuel Economy. Retrieved from http://www.fueleconomy.gov/feg/PowerSearch.do?action=noform \& path=1\&ye

Wikipedia, the free encyclopedia. (2014). Gasoline gallon equivalent. Retrieved from http://en.wikipedia.org/wiki/Gasoline_gallon_equivalent

World Wild Life Fund. (2012). Road transportation emission reduction strategies. Climate change and energy program. Retrieved from http://awsassets.wwf.ca/downloads/road_transportation_emissions_reduction_strategies 2012.pdf.

Wolfram Alpha. (2014). Computational knowledge engine. Retrieved from http://www.wolframalpha.com/input/? $i=114000+$ BTU + per + gallon+to + calories + per + lit $\underline{r e}$ 